\title{
PULMONARY THROMBOEMBOLISM FOLLOWING RADIO- FREQUENCY ABLATION OF THE ATRIOVENTRICULAR NODE IN A PATIENT HETEROZYGOUS FOR THE FACTOR V LEIDEN AND THE MTHFR C677T MUTATIONS
}

\author{
Pešut DP ${ }^{1,2^{*}}$, Raljević $\mathrm{SV}^{2}$, Kontić MDj², Božić DZ², Buha IB ${ }^{2}$, Stević RS ${ }^{1,3}$
}

\begin{abstract}
*Corresponding Author: Dragica P. Pešut, School of Medicine University of Belgrade; Clinical Centre of Serbia, Institute of Lung Diseases and Tuberculosis, Research and Epidemiology Department, 11000 Belgrade, Visegradska 26/20, Serbia; Tel.: +381-11-361-5561; Fax: +381-11-268-1591;

E-mail: dragica.pesut@gmail.com
\end{abstract}

\section{ABSTRACT}

Patients who undergo radiofrequency ablation of the atrioventricular (AV) node rarely develop acute major complications. A 41-year-old Caucasian male smoker, was admitted to the Pulmology Teaching Hospital at Belgrade, Serbia, for sharp persistent chest pain, fever and fatigue following AV node radiofrequency ablation for arrhythmia. Chest X-ray showed obtuse right costo-phrenic angle and laminar atelectasis in the right lower lung lobe. The plasma D-dimer level was elevated. A perfusion lung scan showed multiple bilateral perfusion defects and multislice computed tomography showed thrombotic mass in the right pulmonary artery. Genetic analysis revealed that he was heterozygous for the prothrombin Factor V (FV) Leiden and MTHFR C677T mutations. Therapy started with intravenous heparin, followed by warfarin. He had no other episodes over a 2-year follow-up. Lifelong oral anticoagulant therapy was recommended.

Key words: Thromboembolism, Radiofrequency ablation, Atrioventricular (AV) node, Factor V (FV) Leiden mutation, Risk factor

School of Medicine, University of Belgrade, Internal Medicine Department, Belgrade, Serbia

2 Clinical Centre of Serbia, Teaching Hospital of Lung Diseases, Research and Epidemiology Department, Belgrade, Serbia

3 Clinical Centre of Serbia, Centre of Radiology and Magnetic Resonance, Belgrade, Serbia

\section{INTRODUCTION}

Pulmonary thromboembolism (PTE) is a worldwide problem, particularly in people with known risk factors. The multifactorial nature of PTE necessitates identification of predisposing genetic and environmental risk factors in the patients [1]. Virchow's classic triad of risk-stasis, venous injury, and hypercoagulability-reflects the influence of genetic and environmental risk factors and their interactions [2].

Factor V (FV), Leiden, prothrombin mutation G20210A, deficiency in protein C, protein S, or antithrombin, hyperhomocysteinemia and plasminogen/ fibrinolysis disorders are the most common genetic risk factors for thrombophilia [3]. Factor V Leiden, which causes resistance to activated protein $\mathrm{C}$, is the most common and is caused by a single point mutation (ARG506 to GLN) in the FV gene [4]. This is only found in Caucasians, the prevalence varying between countries. It is associated with a $5-10$-fold increased risk of thrombosis and is found in 20.0-60.0\% of Caucasian patients with thrombosis [4] and is present in approximately $5.0 \%$ of the general population of European origin [2]. We here report on PTE as a rare major complication of a surgical procedure performed on a patient treated for arrhythmia. 


\section{CASE REPORT}

A 41-year-old Caucasian male, smoker (20 cigarettes daily for 20 years), was admitted 2 weeks after an episode of persistent sharp chest pain, fever and fatigue, which occurred soon after slow pathway radiofrequency ablation of the $\mathrm{AV}$, performed because of arrhythmia. There was no family history of thrombosis but no investigation for family thrombophilia was performed.

He was afebrile, with a heart rate of 80 beats $\mathrm{min}^{-1}$, blood pressure $140 / 90 \mathrm{mmHg}$, and a respiratory rate of 18 breaths $\cdot \mathrm{min}^{-1}$. Routine laboratory findings were within normal ranges. Arterial blood gas analysis showed hypoxemia with signs of hyperventilation $\mathrm{PaO}_{2}: 9.2 \mathrm{kPa}$ (standard value 11.28-12.18 kPa), Pa$\mathrm{CO}_{2}: 4.5 \mathrm{kPa}$, saturated oxygen: $95 \%, \mathrm{pH}: 7.47$. An electrocardiogram gave normal results. Standard postero-anterior chest X-ray showed obtuse right costophrenic angle and laminar atelectasis in the right lower lung lobe (Figure 1). D-dimer level, measured by the immunoturbidometric method (Dade-Behring, Deerfield, IL, USA), was $261 \mu \mathrm{g} \cdot \mathrm{L}^{-1}$ (normal $<250 \mu \mathrm{g} \cdot \mathrm{L}^{-1}$ ). A perfusion lung scan showed massive bilateral defects in middle and lower parts of the right lung and segmental defects in basal part of the left lung, which did not correlate with the changes in the chest X-ray (Figure 2). The ventilation scan was not available.

Doppler ultrasonography of the lower limb veins gave negative results fordeep venous thrombosis(DVT). Computed tomography showed a thrombotic mass (12 $\mathrm{mm}$ diameter) in the pulmonary artery. Echocardiography showed increased mean blood pressure in the right ventricle $(27 \mathrm{mmHg})$. Blood tests for antinuclear antibodies (ANA), antineutrophil cytoplasmic antibodies (ANCA) and antiphospholipid antibodies were negative and the level of anticardiolipin antibodies was not elevated. Sputum smear was negative for pathogenic agents including Mycobacteria. Hematological investigation revealed normal activities of protein $\mathrm{C}$, protein S and antithrombin III. DNA analyses for FV Leiden, FII G20210A and MTHFR C677T mutations were performed by polymerase chain reaction (PCR) as previously described $[5,6]$ at the Institute of Molecular Genetics and Bioengineering, Belgrade, Serbia. The PCR analyses for FV Leiden and MTHFR C677T were positive, and both indicated heterozygotes.

Therapy started with intravenous heparin, followed by warfarin, keeping the international rate

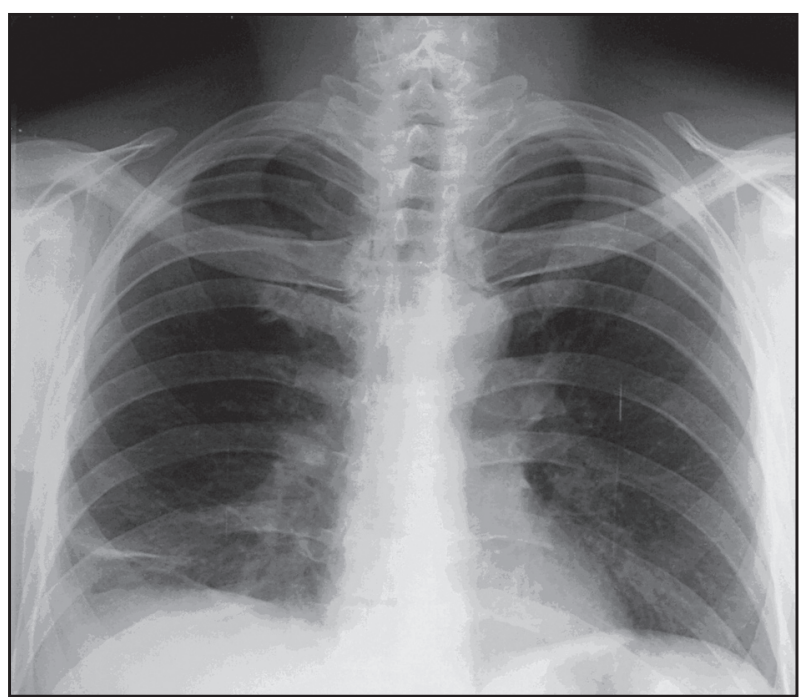

Figure 1. Standard Chest $\mathrm{x}$-ray

The chest radiograph shows changes suggestive of pulmonary thromboembolism: elevation of the right hemi-diaphragm, pleural effusion, and laminar atelectasis

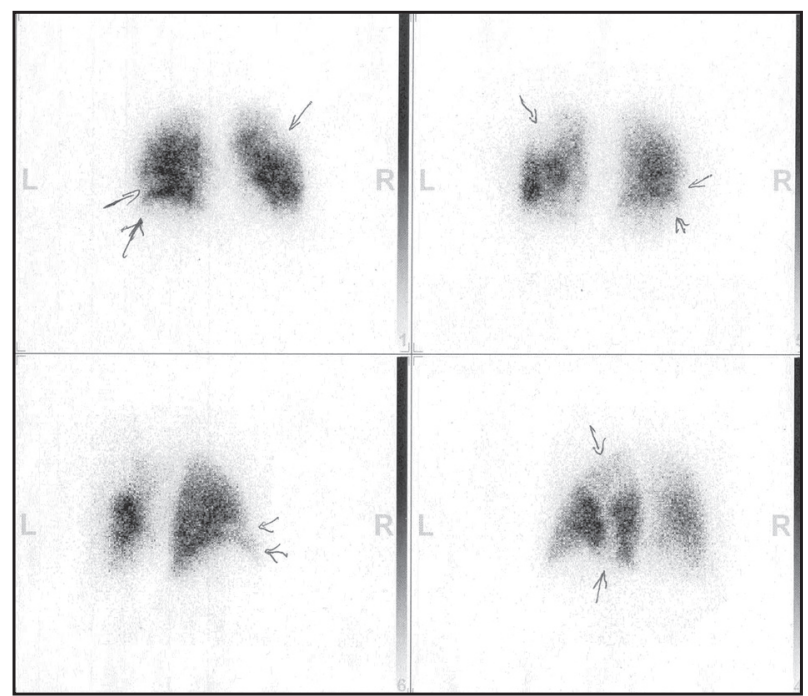

Figure 2. Lung perfusion scintigraphy

Perfusion lung scans show a lateral antero-basal perfusion defect in the lower half of the right lung on antero-posterior (AP) projection, lateral and latero-basal in postero-anterior (PA) projection as well as antero-lateral and antero-basal defect. A larger semi-circle perfusion defect in the upper half of the left lung, laterally both on AP and PA projections, apical hypoperfusion zone and thiny lateral perfusion defect of the left lung.

(INR) of prothrombin time in therapeutic range, i.e., INR $=2-3$. The lifelong oral anticoagulant treatment was recommended. The patient's clinical state gradu- 
ally improved, disease outcome was favorable and computed tomography showed no thrombotic mass in the pulmonary artery after 3 months. During a 2-year follow-up, he had no new thrombotic episodes.

\section{DISCUSSION}

Catheter ablation is a curative treatment with excellent success and minimal complication rates for patients with supraventricular or ventricular arrhythmias both in children and adults [7-9]. Results of a Canadian study, based on a total of 5,330 patients who had catheter ablation performed during a period of 14 years, confirm that radiofrequency ablation was safe and effective, supporting ablation therapy as a firstline therapy for the majority of patients with cardiac arrhythmias [10]. A French retrospective study assessed short- and long-term mortality and morbidity after radiofrequency ablation of the AV node in supraventricular arrhythmias resistant to treatment [11]. Early complications occurred in five out of 91 patients (venous thromboses, PTE, mild pericardial effusion and hemothorax). During 14.5 \pm 8.6 months of followup, 11 patients died, eight of cardiac causes including three of sudden death, unrelated to pacing defects. In a Swedish study on 220 patients, there were six sudden unexplained deaths following the procedure, 14 cardiovascular deaths and 11 deaths from non cardiovascular causes [12]. Five of the patients who died suddenly from cardiovascular causes were autopsied and revealed acute myocardial infarction in four and massive pulmonary embolism in one.

Our case of PTE as a major complication of the radiofrequency electro ablation of $\mathrm{AV}$ node in a heterozygote for FV Leiden and MTHFR C677T mutations is the first case to be reported in Serbian patients. Although the risk in most patients with a thromboembolic complication can be identified, the occurrence of complications is unpredictable. A Czech study that analyzed 400 patients following radiofrequency ablation, identified FV Leiden in one patient who had had a thrombotic episode [13].

The FV Leiden reported prevalences in the normal population and in patients with DVT vary greatly in the literature $[14,15]$ and the risk of venous thrombosis is a 5 - to 8 -fold increased in heterozygotes, whereas the risk in homozygotes is increased 9- to 80-fold $[2,16]$. In the presented case of a heterozygote, the risk of thrombosis was enhanced by the surgical intervention and the presence of another prothrombotic mutation (MTHFR C677T). Women with FV Leiden or with $>1$ prothrombotic polymorphism are particularly predisposed to venous thromboembolism while using contraceptives or during the post partum period [14,17]. Factor V Leiden carriers with locally advanced or metastatic breast cancer have an increased risk of developing catheter-related DVT during chemotherapy [18]. A study indicated that FV Leiden and prothrombin II G20210A, more than MTHFR C677T, are important risk factors for DVT, and that the presence of more than one prothrombotic single nucleotide polymorphism was associated with a significant risk of DVT [19]. Salomon et al. [17] examined three prothrombotic polymorphisms and found each of them to be an independent risk factor, with FV Leiden manifesting the greatest risk and homozygous MTHFR C677T the lowest. The odds ratio for heterozygous individuals, after exclusion of homozygotes, in that study was still high (12.6\%). An enhanced risk of venous thromboembolism in heterozygotes for FV Leiden, when associated with heterozygous factor II G20210A [20,21] or homozygous MTHFR C677T [22], have also been described. However, larger cohorts of patients will have to be studied to substantiate these associations.

Our patient experienced PTE at the age of 41 years. Screening for genetic risk factors is strongly recommended in young patients, in those with recurrent thromboembolism, unprovoked thrombotic or thromboembolic episodes, and in those with thrombosis in an unusual location [1].

Diagnosis of PTE usually includes clinical pretest probability assessment, testing for specific degradation products of cross-linked fibrin (D-dimer), lung scintigraphy and imaging studies. The D-dimer level in our patient was elevated and with the characteristic clinical presentation, positive findings of perfusion scintigraphy and the imaging techniques we performed was highly suggestive of PTE. Rarely, D-dimer level may be within normal limits in PTE [23].

Our report contributes to awareness of the risk of PTE after surgical treatment in patients with genetic disorders that increase thromboembolic risk. Since even a minor surgical procedure may represent a risk factor for thrombosis $[13,23,24]$, proper prophylaxis to prevent serious major complications after interventions should be undertaken to prevent thromboembolism. 


\section{REFERENCES}

1. Tapson VF. Acute pulmonary embolism. N Engl J Med. 2008; 358(10): 1037-1052.

2. Rosendaal FR. Venous thrombosis: the role of genes, environment, and behavior. Hematol Am Soc Hematol Educ Program. 2005:1-12.

3. Rosendaal FR, Koster T, Vandenbroucke JP, Reitsma $\mathrm{PH}$. High risk of thrombosis in patients homozygous for factor $V$ Leiden (activated protein $\mathrm{C}$ resistance). Blood 1995; 85(6): 1504-1508.

4. Zöller B, García de Frutos P, Hillarp A, Dahlbäck B. Thrombophilia as a multigenic disease. Haematologica. 1999; 84(1):59-70.

5. Djordjevic V, Rakicevic L, Gagic M, Nikolic A, Savic A. Simultaneous detection of factor V Leiden and factor II G20210A variants by a multiplex PCR on whole blood. Balkan J Med Genet. 2001; 4(1\&2): 15-17.

6. Djordjevic V, Stankovic M, Nikolic A, Antonijevic N, Rakicevic LJ, Divac A, Radojkovic M. PCR amplification on whole blood samples treated with different commonly used anticoagulants. Pediatr Hematol Oncol. 2006; 23(6): 517-521.

7. Koebe J, Kirchhof P. Novel non-pharmacological approaches for antiarrhythmic therapy of atrial fibrillation. Europace. 2008; 10(4): 433-437.

8. Papagiannis J, Papadopoulou K, Rammos S, Demosthenes Katritsis D. Cryoablation versus radiofrequency ablation for atrioventricular nodal reentrant tachycardia in children: long-term results. Hellenic J Cardiol. 2010; 51(2): 122-126.

9. Lin JL, Stephen Huang SK, Lai LP, Ko WC, Tseng YZ, Lien WP. Clinical and electrophysiologic characteristics and long-term efficacy of slow-pathway catheter ablation in patients with spontaneous supraventricular tachycardia and dual atrioventricular node pathways without inducible tachycardia. J Am Coll Cardiol. 1998; 31(4): 855-860.

10. O'Hara GE, Philippon F, Champagne J, Blier L, Molin F, Côté JM, Nault I, Sarrazin JF, Gilbert M. Catheter ablation for cardiac arrhythmias: a 14-year experience with 5330 consecutive patients at the Quebec Heart Institute, Laval Hospital. Can J Cardiol. 2007; 23(Suppl B): 67B70B. (Erratum: Can J Cardiol. 2009; 25(3): 140.)

11. Mansourati J, Deharo JC, Graux P, Chappuis L, Durieu C, Dutoit A, Guillo P, Djiane P, Blanc JJ. Short and medium-term outcome after radiofrequency ablation of the atrioventricular junction. Arch Mal Coeur Vaiss. 1997; 90(7): 945-951. [Article in French]

12. Darpö B, Walfridsson H, Aunes M, Bergfeldt L, Edvardsson N, Linde C, Lurje L, van der Linden M, Rosenqvist
M. Incidence of sudden death after radiofrequency ablation of the atrioventricular junction for atrial fibrillation. Am J Cardiol. 1997; 80(9): 1174-1177.

13. Haman L, Parízek P, alý R, Duda J, Malý J. Analysis of thrombotic complications after catheter ablation. Acta Medica (Hradec Kralove). 2006; 49(1): 47-50.

14. Aznar J, Vaya A, Estelles A, Mira Y, Segui R, Villa P, Ferrando F, Falco C, Corella D, Espana F. Risk of venous thrombosis in carriers of the prothrombin G20210A variant and factor V Leiden and their interaction with oral contraceptives. Haematologica. 2000; 85(12): 1271-1276.

15. Coen D, Zadro R, Honovic L, Banfic L, Stavljenic Rukavina A. Prevalence and association of the factor $\mathrm{V}$ Leiden and prothrombin G20210A in healthy subjects and patients with venous thromboembolism. Croat Med J. 2001; 42(4): 488-492.

16. Koster T, Rosendaal FR, de Ronde H, Briet E, Vandenbroucke JP, Bertina RM. Venous thrombosis due to a poor anticoagulant response to activated protein $\mathrm{C}$ : Leiden Thrombophilia Study. Lancet. 1993; 342(88868887): 1503-1506.

17. Salomon O, Steinberg DM, Zivelin A, Gitel S, Dardik R, Rosenberg N, Berliner S, Inbal A, Many A, Lubetsky A, Varon D, Martinowitz U, Seligsohn U. Single and combined prothrombotic factors in patients with idiopathic venous thromboembolism: prevalence and risk assessment. Arterioscler Thromb Vasc Biol. 1999; 19(3): 511-518.

18. Mandala M, Curigliano G, Bucciarelli P, Ferretti G, Mannucci PM, Colleoni M, Ventura A, Peruzzotti G, Severi G, Pelicci PG, Biffi R, Orsi F, Cinieri S, Goldhirsch A. Factor V Leiden and G20210A prothrombin mutation and the risk of subclavian vein thrombosis in patients with breast cancer and a central venous catheter. Ann Oncol. 2004; 15(4): 590-593.

19. Almawi WY, Tamim H, Kreidy R, Timson G, Rahal E, Nabulsi M, Finan RR, Irani-Hakime N. A case control study on the contribution of factor V-Leiden, prothrombin G20210A, and MTHFR C677T mutations to the genetic susceptibility of deep venous thrombosis. J Thromb Thrombolysis. 2005; 19(3): 189-196.

20. Makris M, Preston FE, Beauchamp NJ, Cooper PC, Daly ME, Hampton KK, Bayliss P, Peake IR, Miller GJ. Co-inheritance of the 20210A allele of the prothrombin gene increases the risk of thrombosis in subjects with familial thrombophilia. Thromb Haemost. 1997; 78(6): 1426-1429.

21. Howard TE, Marusa M, Boisza J, Young A, Sequeira J, Channell C, Guy C, Benson E, Duncan A. The prothrombin gene 3'-untranslated region mutation is frequently associated with factor $\mathrm{V}$ Leiden in thrombo- 
philic patients and shows ethnic-specific variation in allele frequency. Blood. 1998; 91(3):1092-1093.

22. Cattaneo M, Tsai MY, Bucciarelli P, Taioli E, Zighetti ML, Bignell M, Mannucci PM. A common mutation in the methylenetetrahydrofolate reductase gene (C677T) increases the risk for deep vein thrombosis in patients with mutant factor $\mathrm{V}$ (factor $\mathrm{V}: \mathrm{Q}^{506}$ ). Arterioscler Thromb Vasc Biol. 1997; 17(9): 1662-1666.
23. Nagorni-Obradovic Lj, Miljic P, Djordjevic V, Pesut D, Jovanovic D, Stojsic J, Stevic R, Radojkovic D. The prothrombin factor II G20210A mutation with pulmonary thromboembolism and a normal level of fibrin degradating products. Balkan J Med Genet. 2009; 12(2): 69-76.

24. Yamamoto T, Ito M, Nagata S, Suzuki H, Tagawa A, Nagase M, Hishida AJ. Catastrophic exacerbation of antiphospholipid syndrome after lung adenocarcinoma biopsy. J Rheumatol. 2000; 27(8): 2035-2037. 